\title{
High Hospital Volume Is Associated with Better Outcomes for Breast Cancer Surgery: Analysis of 233,247 Patients
}

\author{
Ulrich Guller, M.D., MHS, ${ }^{1,2}$ Shawn Safford, M.D. ${ }^{3}$ Ricardo Pietrobon, M.D., Ph.D, ${ }^{2,4}$ Michael Heberer, M.D., MBA, \\ Daniel Oertli, M.D., FACS, ${ }^{1}$ Nitin B. Jain, M.D., MSPH ${ }^{2}$ \\ ${ }^{1}$ Department of Surgery, Divisions of General Surgery and Surgical Research, University of Basel, Spitalstrasse 21, CH-4031, Basel, Switzerland \\ ${ }^{2}$ Center for Excellence in Surgical Outcomes, Duke University Medical Center, Durham, North Carolina 27710, USA \\ ${ }^{3}$ Department of Surgery, Duke University Medical Center, Durham, North Carolina 27710, USA \\ ${ }^{4}$ Division of Orthopedic Surgery, Duke University Medical Center, Durham, North Carolina 27710, USA
}

Published Online: June 30, 2005

\begin{abstract}
Background: The relationship between hospital volume and outcomes needs to be further elucidated for low-risk procedures such as surgical therapy of localized breast cancer. The objective of this investigation was to assess the relationship between hospital volume and outcomes for breast cancer surgery. Methods: A total of 233,247 patients who underwent breastconserving therapy (BCT) and breast-ablative therapy (BAT) for localized breast cancer were extracted from 13 years (1988-2000) of the Nationwide Inpatient Samples. Hospital volume was classified as low ( $<30$ cases/year), intermediate ( $\geq 30$ to $<70$ cases/year), and high ( $\geq 70$ cases/year). Multiple linear and logistic regression analyses were used to assess the risk-adjusted association between hospital volume and outcomes. Results: In risk-adjusted analyses, patients operated on at low-volume hospitals were $3.04(p=0.03)$ times more likely to die after BCT compared with patients operated on at high-volume hospitals. Similarly, low-volume hospitals had a significantly higher likelihood of postoperative complications (odds ratio $[\mathrm{OR}]=1.73, p=0.01$ for $\mathrm{BCT}$; $\mathrm{OR}=1.44, p<0.001$ for $\mathrm{BAT}$ ) compared with high-volume hospitals. Compared with low-volume hospitals, length of hospital stay was significantly shorter and nonroutine patient discharge significantly lower for high-volume providers for both BCT and BAT (all $p<0.001$ ). Patients were also significantly less likely to undergo BCT if operated on in a low- or intermediate-volume hospital compared with a high-volume provider $(p<0.001)$. Conclusions: Highvolume hospitals had significantly lower nonroutine patient discharge, postoperative morbidity and mortality, shorter length of hospital stay, and higher likelihood of performing BCT. Referral of patients with localized breast cancer to high-volume hospitals may be justified.
\end{abstract}

The relationship between hospital volume and outcomes has come to the forefront of public debate in recent years. Many studies have attempted to address this relationship for a broad range of surgical diseases [1-4]. The majority of these studies involving cancer patients have evaluated high-risk procedures which are associated with high mortality rates [3]. In contrast, the volume-outcomes relationship for routinely performed low-risk procedures such as breast-conserving therapy (BCT) or mastectomy has been poorly studied.

Correspondence to: Ulrich Guller, M.D., MHS, e-mail: uguller@yahoo. com
The aging of our population results in increased incidence of breast cancer and subsequent surgical treatment. The current surgical management of localized breast cancer includes BCT and breast-ablative therapy (BAT). Both procedures carry a low risk for morbidity and mortality. A few studies to date have evaluated long-term patient survival, assessing the combination of medical and surgical care [5-7]. However, to our knowledge no investigation has assessed perioperative outcomes for breast cancer patients undergoing BCT and BAT. We thus performed an analysis of over 233,000 patients from 13 consecutive years of the Nationwide Inpatient Samples database to evaluate the association between hospital volume and in-hospital morbidity and mortality, length of stay, discharge status, and the likelihood of undergoing BCT. Our a priori hypothesis was that high-volume hospitals have better outcomes compared with intermediate- and low-caseload providers.

\section{Materials and Methods}

Database Description.

The Nationwide Inpatient Samples for the years 1988 through 2000 were used for this study [8]. The Nationwide Inpatient Samples are part of the Healthcare Cost and Utilization Project (HCUP), sponsored by the Agency for Healthcare Research and Quality (AHRQ) and is among the largest publicly available inpatient databases in the United States, containing 5-8 million records of inpatient stays. Patients are sampled from about 750 to 1000 US community hospitals each year. The Nationwide Inpatient Samples approximate $20 \%$ stratified probability samples representative of community hospitals in the United States. To ensure maximal representativeness of the US population, sampling strata were used for the creation of the Nationwide Inpatient Samples based on five hospital characteristics (geographic region, ownership, urban/rural location, teaching status, and bed size). The datasets provide the following information: hospital identifiers, patient demographics, length of hospital stay, vital status, patient discharge status, and 
procedure and diagnoses codes classified according to the International Classification of Diseases, 9th ed. Clinical Modification (ICD-9-CM).

The HCUP assigned validation and quality assessment of these datasets to an independent contractor [8]. The validation was performed by reviewing univariate statistics for all numeric data elements, reviewing frequency distributions for all categorical and some continuous data elements, checking ranges against standard norms, and performing edit checks to identify inconsistencies between related data elements. Furthermore, the Nationwide Inpatient Samples compared favorably with the National Hospital Discharge Survey (NHDS), and was described to perform very well for many estimates $[9,10]$.

\section{Sample Selection}

Patients were included in the present analysis if they were female and had either BCT (ICD-9 codes 85.21, 85.22, 85.23) or BAT (ICD-9 codes 85.41, 85.43) for breast cancer (ICD-9 codes 174.0, 174.1, 174.2, 174.3, 174.4, 174.5, 174.6, 174.8, 174.9). Breast cancer patients who underwent bilateral breast cancer surgery (ICD-9 codes 85.42, 85.44, 85.46, 85.48, or two of the following procedure codes occurring in any combination: 85.21, 85.22, 85.23), radical mastectomy (ICD-9 code 85.45), or extended radical mastectomy (ICD-9 code 85.47) were excluded from our investigation. Also, patients with metastatic disease (except to regional lymph nodes: ICD-9 code 196.3) were excluded. The exclusion criteria were applied to impart homogeneity to our patient population. We performed stratified analyses based on whether BCT or BAT was performed.

\section{Outcome Measures}

The outcomes of interest included length of hospital stay, nonroutine patient discharge, postoperative in-hospital complications, all-cause in-hospital mortality, and the likelihood of undergoing BCT. Length of hospital stay (measured in days) was defined as the difference between date of admission and date of discharge of the patient. All-cause, nonfatal in-hospital morbidity assessed based on ICD-9 diagnoses codes.

Complications included mechanical wound complications, infections, and complications occurring during the procedure (Appendix). All-case in-hospital mortatliy was assessed based on information regarding vital status at discharge.

Another end point that was assessed in the present investigation was the patient's discharge status. The Nationwide Inpatient Samples provide the following information regarding a patient's discharge status: (1) routine discharge from the hospital, (2) discharge to another hospital, (3) discharge to a nursing facility, (4) discharge to intermediate care, (5) discharge to another type of facility, (6) discharge to home with home health care, (7) discharge against medical advice, (8) death. Patients who died during hospitalization $(n=214,0.09 \%)$ and patients who left the hospital against medical advice $(n=89$, $0.04 \%$ ) were excluded from the analysis of this specific end point. The remaining patients were divided into routine discharge (the desired outcome) versus nonroutine discharge (a negative outcome).

Finally, the likelihood of a patient undergoing BCT versus BAT was also assessed.

\section{Primary Predictor Variable}

The primary predictor variable was annual hospital volume. Each hospital had a unique hospital identifier which was used to calculate hospital volume separately for BCT and BAT. Hence, hospital volume reflects only surgical volume of BCT and BAT and not total surgical volume.

Hospital volume was divided into three categories (low volume: $<30$, intermediate volume: $\geq 30$ to $<70$, and high volume: $\geq 70$ procedures/year). These categories were chosen to obtain approximately similar percentages of procedures in each category and also to have clinically meaningful cutoffs.

\section{Covariates}

Covariates obtained from the Nationwide Inpatient Samples included age (years), race, household income (median household income of patient's ZIP code, 3 categories: 1 \$1-25,000, $2=25,001-35,000,3=35,001$ and above, a known proxy for a patient's socioeconomic status), teaching status and location of hospital (rural nonteaching, urban nonteaching, urban teaching hospital), and patients comorbidity (Charlson index modified by Deyo) $[11,12]$. The Charlson index modified by Deyo measures comorbidity by assigning scores of 1, 2, 3, or 6 to each of a patient's comorbid conditions. These scores are then added up to a single index score, which reflects the overall comorbidity of the patient. The hospital's teaching status was obtained from the AHA Annual Survey of Hospitals. A hospital is considered to be a teaching hospital if it has an AMA-approved residency program, is a member of the Council of Teaching Hospitals (COTH), or has a ratio of fulltime equivalent interns and residents to beds of 0.25 or higher [8].

\section{Statistical Analysis}

Each of the analyses mentioned below was performed separately for both BCT and BAT procedures. Bivariate analyses were performed to assess the unadjusted association between hospital volume and outcomes. Multivariable regression analyses were used to examine the risk-adjusted association between hospital volume and outcomes. All multivariable analyses were adjusted for the following potential confounders: age, race, household income, teaching status and location of the hospital, and patient comorbidity. Multivariable regression analyses allow the assessment of the risk-adjusted (independent of other potential confounders) impact of hospital volume on the outcomes. Differences between the potential confounders are thus decreased using this method.

Risk-adjusted odds ratios with $95 \%$ confidence intervals (CI) and $p$ values were used to assess the strength of the association between hospital volume and the outcomes. Adjusted estimates were calculated for length of stay using linear regression.

Statistical analyses were conducted using Intercooled STATA for Windows (version 7.0) (Stata Corporation, College Station, TX) and SAS for Windows (version 8.02) (SAS Institute Inc., Cary, NC).

\section{Results}

The combined datasets contain information on 233,247 patients who underwent breast cancer surgery. Of these, 52,483 $(22.5 \%)$ patients underwent BCT and 180,764 (77.5\%) patients had BAT.

Patients included in our analysis were predominantly white (58.9\% for BCT and $53.0 \%$ for BAT), and had a median age of 62.0 years (interquartile range: 22.0 years) and 65.0 years (inter- 
Table 1. Characteristics of patients undergoing breast cancer surgery

\begin{tabular}{|c|c|c|}
\hline Baseline characteristics & $\begin{array}{l}\text { Breast-conserving } \\
\text { therapy }(n=52,483)\end{array}$ & $\begin{array}{l}\text { Breast-ablative } \\
\text { therapy }(n=180,764)\end{array}$ \\
\hline \multicolumn{3}{|l|}{ Age } \\
\hline $\begin{array}{l}\text { Median (yr) } \\
\quad \text { [Interquartile range] }\end{array}$ & $62.0[22.0]$ & $65.0[22.0]$ \\
\hline Missing & $0.02 \%$ & $0.03 \%$ \\
\hline \multicolumn{3}{|l|}{ Gender } \\
\hline Female $^{\mathrm{a}}$ & $100 \%$ & $100 \%$ \\
\hline \multicolumn{3}{|l|}{ Race } \\
\hline White & $58.9 \%$ & $53.0 \%$ \\
\hline African-American & $5.6 \%$ & $5.0 \%$ \\
\hline Hispanic & $2.6 \%$ & $2.4 \%$ \\
\hline Other & $1.8 \%$ & $1.8 \%$ \\
\hline Missing & $31.1 \%$ & $37.8 \%$ \\
\hline \multicolumn{3}{|l|}{ Income } \\
\hline$\$ 1-25,000$ & $16.5 \%$ & $23.2 \%$ \\
\hline$\$ 25.001>-35.000$ & $31.9 \%$ & $36.1 \%$ \\
\hline$\$ 35,001$ and above & $48.4 \%$ & $37.3 \%$ \\
\hline Missing & $3.2 \%$ & $3.4 \%$ \\
\hline $\begin{array}{l}\text { Median Deyo score } \\
{\text { [interquartile range }{ }^{a}}\end{array}$ & $2.0[6.0]$ & $2.0[6.0]$ \\
\hline 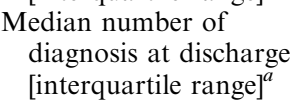 & $2.0 .[3.0]$ & $3.0[2.0]$ \\
\hline $\begin{array}{l}\text { Patients operated in } \\
\text { low-volume hospitals }\end{array}$ & $12,081(23.0 \%)$ & $58,697(32.5 \%)$ \\
\hline $\begin{array}{l}\text { Patients operated in } \\
\text { intermediate-volume } \\
\text { hospitals }\end{array}$ & $19,549(37.3 \%)$ & $65,786(36.4 \%)$ \\
\hline $\begin{array}{l}\text { Patients operated in } \\
\text { high-volume hospitals }\end{array}$ & $20,853(39.7 \%)$ & $56,281(31.1 \%)$ \\
\hline
\end{tabular}

${ }^{\mathrm{a}}$ Indicates that there were no missing values.

Table 2. Unadjusted outcomes of patients undergoing breast surgery

\begin{tabular}{lll}
\hline Outcomes & $\begin{array}{l}\text { Breast-conserving } \\
\text { therapy }(n=52,483)\end{array}$ & $\begin{array}{l}\text { Breast-ablative } \\
\text { therapy }(n \text { 180,764) }\end{array}$ \\
\hline $\begin{array}{l}\text { Length of stay in } \\
\text { days (median) } \\
\quad \text { interquartile range }]\end{array}$ & $2.0[1.0]$ & $3.0[2.0]$ \\
$\begin{array}{l}\text { Missing } \\
\text { Mortality }\end{array}$ & $82(0.2 \%)$ & $255(0.1 \%)$ \\
$\quad \begin{array}{l}\text { Died } \\
\text { Missing }\end{array}$ & $55(0.1 \%)$ & $159(0.1 \%)$ \\
$\begin{array}{l}\text { Postoperative complications } \\
\text { Present }\end{array}$ & $27(0.05 \%)$ & $79(0.04 \%)$ \\
$\quad$ Missing & $259(0.5 \%)$ & $1,329(0.7 \%)$ \\
Patient discharge status & $0 \%$ & $0 \%$ \\
$\quad$ Nonroutine & $5,111(9.7 \%)$ & $23,705(13.1 \%)$ \\
Missing & $115(0.2 \%)$ & $294(0.2 \%)$ \\
\hline
\end{tabular}

quartile range: 22.0 years) for BCT and BAT, respectively. The median comorbidity score was 2.0 (interquartile range: 6.0 ) for patients undergoing BCT and BAT (Table 1).

The median lengths of hospital stay for patients undergoing BCT and BAT were 2.0 days (interquartile range: 1.0 day) and 3.0 days (interquartile range: 2 days), respectively. Postoperative complications were uncommon, affecting $0.5 \%$ of BCT and $0.7 \%$ of BAT patients. Nonroutine disposition was recorded for $9.7 \%$ of patients undergoing BCT and $13.1 \%$ of those having BAT. Inhospital mortality was $0.1 \%$ for both BCT and BAT (Table 2).

For all outcomes except in-hospital morbidity after BAT, lowvolume providers had the worst outcomes, followed by those with intermediate caseload, while high-volume providers had the best outcomes (Tables 3 and 4).
Table 3. Stratified unadjusted outcomes by hospital volume

\begin{tabular}{lccc}
\hline & Hospital volume & $\begin{array}{l}\text { Unadjusted } \\
\text { percentages }\end{array}$ & $p$ Value \\
Outcome & & & \\
\hline Breast-conserving therapy $(\boldsymbol{n}=\mathbf{5 2 , 4 8 3})$ & & \\
Mortality & $<30$ & $0.24 \%$ & $<0.001$ \\
& $\geq 30$ to $<70$ & $0.1 \%$ & \\
& $\geq 70$ & $0.03 \%$ & 0.002 \\
Postoperative & $<30$ & $0.69 \%$ & \\
complications & $\geq 30$ to $<70$ & $0.48 \%$ & \\
& $\geq 70$ & $0.40 \%$ & \\
Nonroutine & $<30$ & $12.2 \%$ & \\
patient discharge & $\geq 30$ to $<70$ & $9.8 \%$ & \\
& $\geq 70$ & $8.3 \%$ & \\
Breast-ablative therapy & $(\boldsymbol{n}=\mathbf{1 8 0 , 7 6 4 )}$ & & \\
Mortality & $<30$ & $0.12 \%$ & \\
& $\geq 30$ to $<70$ & $0.08 \%$ & \\
Postoperative & $\geq 70$ & $0.06 \%$ & \\
complications & $\geq 30$ & $0.92 \%$ & \\
& $\geq 30$ to $<70$ & $0.62 \%$ & \\
Nonroutine & $<30$ & $0.67 \%$ & \\
patient discharge & $\geq 30$ to 70 & $15.8 \%$ & \\
& $\geq 70$ & $12.8 \%$ & \\
\hline
\end{tabular}

Table 3a. Continuation

\begin{tabular}{llll}
\hline & & $\begin{array}{l}\text { Length of } \\
\text { hospital stay } \\
\text { (days) }\end{array}$ & $p$ Value \\
\hline $\begin{array}{l}\text { Breast-conserving } \\
\text { therapy }(\boldsymbol{n}=\mathbf{5 2 , 4 8 3})\end{array}$ & Hospital volume & & \\
& $<30$ & 2.61 & $<0.001$ \\
& $\geq 30$ to $<70$ & 2.27 & \\
Breast-ablative & $\geq 70$ & 2.00 & \\
therapy $(\boldsymbol{n}=\mathbf{1 8 0 , 7 6 4})$ & & & \\
& $<30$ & 3.31 & \\
& $\geq 30$ to $<70$ & 3.24 & \\
& $\geq 70$ & 3.18 & \\
\hline
\end{tabular}

Table 4. Unadjusted proportions of patients undergoing breast-conserving therapy by hospital volume

\begin{tabular}{llr}
\hline Hospital volume & $\begin{array}{l}\text { Percentage of patients undergoing } \\
\text { breast-conserving therapy }\end{array}$ & $p$ Value \\
\hline$<30$ & $17.1 \%$ & $<0.001$ \\
$\geq 30$ to $<70$ & $22.9 \%$ & \\
$>70$ & $26.9 \%$ & \\
\hline
\end{tabular}

In risk-adjusted multiple linear regression analysis, length of hospital stay was significantly longer for low-volume hospitals after $\mathrm{BCT}$ and $\mathrm{BAT}$ compared with high-volume providers (all $p$ $\leq$ 0.001, Table 5).

Patients who had BCT in low-volume hospitals had an odds ratio of in-hospital mortality of 3.04 (95\% CI: [1.12, 8.24], $p=0.03$ ) when compared with high-volume hospitals after riskadjusting for putative confounding factors (Table 6). For patients who had BAT, the risk-adjusted odds ratios for in-hospital mortality were 1.90 (95\% CI: [0.97, 3.70], $p=0.06$ ) for low-volume and $1.78(95 \% \mathrm{CI}[0.95,3.30] p=0.07)$ for intermediate-volume hospitals compared with high-volume hospitals (Table 6). Lowvolume hospitals had significantly higher postoperative complications for both $\mathrm{BCT}(\mathrm{OR}=1.73,95 \% \mathrm{C} 1:[1.17,2.56], p=0.01)$ 
Table 5. Risk-adjusted ${ }^{\mathrm{a}}$ associations between hospital volume and length of hospital stay after breast cancer surgery

\begin{tabular}{clll}
\hline & $\begin{array}{l}\text { Adjusted } \\
\text { estimate of } \\
\text { LOS }\end{array}$ & (SD) & $p$ Value \\
\hline $\begin{array}{c}\text { Hospital volume } \\
\text { Breast-conserving therapy } \\
<30\end{array}$ & 2.46 & $(0.74)$ & $<0.001$ \\
$\geq 30$ to $<70$ & 2.11 & $(0.67)$ & $<0.001$ \\
$\geq 70$ & 1.93 & $(0.64)$ & Ref. \\
$\begin{array}{c}\text { Breast-ablative therapy } \\
<30\end{array}$ & 3.09 & $(0.43)$ & $<0.001$ \\
$\geq 30$ to $<70$ & 2.99 & $(0.44)$ & 0.34 \\
$\geq 70$ & 2.97 & $(0.42)$ & Ref \\
\hline
\end{tabular}

LOS $=$ length of hospital stay, $\mathrm{SD}=$ standard deviation, Re-

$\mathrm{f}=$ High-volume providers are the reference category.

${ }^{a}$ Risk-adjusted for age, race, household income, teaching status, and location of the hospital, and patients comorbidity.

Table 6. Risk-adjusted ${ }^{\mathrm{a}}$ associations between hospital volume and mortality, postoperative complications, and nonroutine patient discharge of breast cancer patients

\begin{tabular}{|c|c|c|c|c|}
\hline Outcome & Procedure volume & $\begin{array}{l}\text { Adjusted } \\
\text { odds ratio }\end{array}$ & $(95 \% \mathrm{CI})$ & $p$ Value \\
\hline \multicolumn{5}{|c|}{ Breast-conserving therapy } \\
\hline \multirow[t]{3}{*}{ Mortality } & $<30$ & 3.04 & $(1.12,8.24)$ & 0.03 \\
\hline & $\geq 30$ to $<70$ & 1.60 & $(0.59,4.33)$ & 0.35 \\
\hline & $\geq 70$ & Ref & - & \\
\hline Postoperative & $<30$ & 1.73 & $(1.17,2.56)$ & 0.01 \\
\hline complications & $\begin{array}{l}\geq 30 \text { to }<70 \\
\geq 70\end{array}$ & $\begin{array}{l}1.14 \\
\text { Ref }\end{array}$ & $(0.81,1.62)$ & 0.45 \\
\hline \multirow{2}{*}{$\begin{array}{l}\text { Nonroutine } \\
\text { patient discharge }\end{array}$} & $<30$ & 1.55 & $(1.40,1.71)$ & $<0.001$ \\
\hline & $\begin{array}{l}\geq 30 \text { to }<70 \\
\geq 70\end{array}$ & $\begin{array}{l}1.23 \\
\text { Ref }\end{array}$ & $(1.13,1.34)$ & $<0.001$ \\
\hline \multicolumn{5}{|c|}{ Breast-ablative therapy } \\
\hline \multirow[t]{2}{*}{ Mortality } & $<30$ & 1.90 & $(0.97,3.70)$ & 0.06 \\
\hline & $\begin{array}{l}\geq 30 \text { to }<70 \\
\geq 70\end{array}$ & $\begin{array}{l}1.78 \\
\text { Ref }\end{array}$ & $(0.95,3.30)$ & 0.07 \\
\hline & $<30$ & 1.44 & $(1.21,1.72)$ & $<0.001$ \\
\hline complications & $\begin{array}{l}\geq 30 \text { to }<70 \\
\geq 70\end{array}$ & $\begin{array}{l}0.91 \\
\text { Ref }\end{array}$ & $(0.77,1.07)$ & 0.26 \\
\hline \multirow{2}{*}{$\begin{array}{l}\text { Nonroutine } \\
\text { patient discharge }\end{array}$} & $<30$ & 1.56 & $(1.49,1.65)$ & $<0.001$ \\
\hline & $\begin{array}{l}\geq 30 \text { to }<70 \\
\geq 70\end{array}$ & $\begin{array}{l}1.25 \\
\text { Ref }\end{array}$ & $(1.19,1.31)$ & $<0.001$ \\
\hline
\end{tabular}

Ref-high-volume providers are the reference category, $\mathrm{CI}=$ confidence interval.

${ }^{a}$ Risk-adjusted for age, race, household income, teaching status and location of the hospital, and patients comorbidity.

and BAT $(\mathrm{OR}=1.44,95 \% \mathrm{CI}:[1.21,1.72], p<0.001$ when compared with high-volume hospitals.

Nonroutine patient discharge was significantly higher in low and intermediate-volume hospitals for both BCT and BAT compared with high-volume hospitals (all $p<0.001$ ). Finally, patients operated on in low- $(\mathrm{OR}=0.72 ; 95 \% \mathrm{CI}$ : [0.69, 0.74], $p$ $<0.001)$ and intermediate- $(\mathrm{OR}=0.92 ; 95 \% \mathrm{CI}$ : [0.89, 0.95], $p<$ $0.001)$ volume hospitals were significantly less likely to undergo BCT compared with patients undergoing breast cancer surgery in high-volume hospitals (Table 7).

\section{Discussion}

The present investigation, based on 13 years of nationally representative databases, provides compelling evidence that patients treated at high-volume hospitals have consistently better clinical and economic outcomes such as significantly decreased length of
Table 7. Risk-adjusted ${ }^{a}$ likelihood of undergoing breast-conserving therapy

\begin{tabular}{lllc}
\hline & $\begin{array}{l}\text { Adjusted odds ratio of } \\
\text { likelihood of undergoing } \\
\text { breast-conserving therapy }\end{array}$ & $(95 \% \mathrm{CI})$ & $p$ Value \\
Procedure volume & 0.72 & $(0.69,0.74)$ & $<0.001$ \\
$<30$ & 0.92 & $(0.89,0.95)$ & $<0.001$ \\
$\geq 30$ to $<70$ & Ref & - & \\
$\geq 70$ & &
\end{tabular}

Ref $=$ high-volume providers are the reference category,

$\mathrm{CI}=$ Confidence interval.

${ }^{a}$ Risk-adjusted for age, race, household income, teaching status and location of the hospital, and patients' comorbidity.

hospital stay, postoperative complications, nonroutine patient discharges, and mortality. Also, our study found that patients treated in high-volume hospitals had a significantly higher likelihood of undergoing BCT, and therefore stresses the importance of hospital volume on low-risk operations such as BCT and BAT for localized breast cancer.

Patient outcomes have been linked to hospital volume in various surgical diseases [1-4]. In large comprehensive studies, mortality decreased as volume increased for major cancer operations including colectomy, gastrectomy, esophagectomy, liver resection, pancreatic resection, nephrectomy, and cystectomy [1, 4, 13]. These cancers are treated with high-risk operations that are associated with significant morbidity and mortality because of their technical complexity. Emphasis of volume-outcomes research has been directed toward these high-risk procedures. Large differences in mortality rates between high-and low-volume providers have been noted, resulting in many preventable surgical deaths each year [2]. However, the impact of hospital volume on frequent low-risk surgeries such as BCT and BAT has been poorly studied.

A few investigations have focused on the impact of hospital volume on long-term survival for breast cancer patients [7, 14]. While Harcourt et al. [14] did not find a significant volume-outcome relationship, Roohan et al. [7] reported that high hospital volume was positively associated with improved 5-year survival. This advantage remained statistically significant even after riskadjusting for several clinical and sociodemographic variables. While these previous investigations evaluated a long-term outcome of patients with breast cancer, we have attempted to delineate the specific impact of hospital volume on the choice of treatment, inhospital adverse events and economic outcomes such as length of hospital stay and rate of nonroutine patient discharge.

We found a significantly increased mortality rate after BCT in hospitals where less than 30 cases per year were performed. Also, postoperative in-hospital complications were significantly higher in low-volume hospitals for both BCT and BAT. It is clear that a patient is highly unlikely to die from breast cancer surgery in and of itself. However, it can be hypothesized that high-volume hospitals have a better pre-, peri-, and postoperative management of patients. It is possible that the collaboration between physicians, nursing staff, anesthesiologists, physical therapists, and other ancillary services in high-volume centers is superior compared with that in low-volume hospitals. This higher level of collaboration between the entire team caring for the patient is likely to decrease the in-hospital mortality.

To further elucidate the effect of hospital volume on resource use, we evaluated outcomes such as length of hospital stay and nonroutine patient discharge. We found that low-volume hospi- 
tals had a significantly higher rate of nonroutine patient discharges, with risk-adjusted odds ratios exceeding 1.5 for both BCT and BAT. Similarly, we found significantly longer lengths of stay with decreasing hospital volume. While the risk-adjusted difference between high- and low-volume hospitals for length of hospital stay after BAT was small, it was more than half a day for BCT. These results are not only statistically significant but also important from an economic perspective, considering that longer length of stay and increased nonroutine patient discharge are correlated with higher costs.

Finally, we found that patients who were treated at high-volume centers were significantly more likely to undergo BCT. It is well established and generally accepted that BCT and mastectomy are equally efficient regarding disease-free and overall survival in the treatment of early-stage breast cancer $[15,16]$. However, lumpectomy is a less invasive procedure with better results with respect to body image [17-20], sexual function [18, 19], and quality of life [21]. The statistically and clinically significant differences in undergoing $\mathrm{BCT}$ between low- and high-volume providers are among the most important and relevant findings of the present investigation.

The limitations of our study are those of an administrative database analysis. First, the Nationwide Inpatient Samples database contains only inpatient data, and thus long-term outcomes such as disease-free and overall survival could not be assessed. Second, although we performed multiple logistic and linear regression analyses, adjusting for many potential patient and hospital level confounders, we were unable to adjust for time of diagnosis, tumor size, location, and grade of the breast cancer, whether axillary lymph node dissection was performed, and whether the patient underwent mammography screening or had access to postoperative radiotherapy. Third, it would have been interesting to assess the cause of death of patients who died during hospitalization. However, this information can not be ascertained from the Nationwide Inpatient Samples.

In summary, our study supports the conclusion that high-volume hospitals are consistently associated with better clinical and economic outcomes for breast cancer surgery. Referral of patients with localized breast cancer to high-volume hospitals may be justified. It is likely that our results for breast cancer surgery can be generalized to other low-risk surgical procedures. However, further studies are needed to validate these assumptions.

\section{Acknowledgments}

The authors thank the Swiss National Foundation, Bern, Switzerland; Krebsliga beider Basel, Basel, Switzerland; Freiwillige Akademische Gesellschaft, Basel, Switzerland; and Fondazione Gustav e Ruth Jacob, Aranno, Switzerland, for their financial support of Dr. Guller's research fellowship at the Duke University Medical Center. The authors thank the Division of Orthopedic Surgery, Duke University Medical Center, Durham, North Carolina, purchasing the Nationwide Inpatient Samples 1988-2000.

\section{Appendix: Postoperative In-Hospital Morbidity}

\section{A. Mechanical wound complications:}

Delayed wound healing: 998.83

Postoperative hematoma: 998.12

Disruption of operative wound: 998.3

Persistent postoperative fistula: 998.6

Emphysema resulting from procedure: 998.81

\section{B. Infections:}

Postoperative skin abscess: 998.59

Postoperative septic wound complications: $\mathbf{9 9 8 . 5 9}$

Postoperative skin infection: 998.59

Postoperative infected seroma: 998.51

\section{Complications during procedure:}

Accidental puncture or laceration, complicating surgery: 998.2 Foreign body accidentally left during procedure: $\mathbf{9 9 8 . 4}$ Bleeding complicating procedure: $\mathbf{9 9 8 . 1 1}$

\section{References}

1. Begg CB, Cramer LD, Hoskins WJ, et al. Impact of hospital volume on operative mortality for major cancer surgery. JAMA 1998;280:1747-1751

2. Halm EA, Lee C, Chassin MR. Is volume related to outcome in health care? A systematic review and methodolgic critique of the literature. Ann. Intern. Med. 2002;137:511-520

3. Hillner BE, Smith TJ, Desch CE. Hospital and physician volume or specialization and outcomes in cancer treatment: importance in quality of cancer care. J. Clin. Oncol. 2000;18(11):2327-2340

4. Birkmeyer JD, Siewers AE, Finlayson EVA, et al. Hospital volume and surgical mortality in the United States. N. Engl. J. Med. 2002;346:1128-1137

5. Gillis CR, Hole DJ. Survival outcome of care by specialist surgeons in breast cancer: a study of 3786 patients in the west of Scotland. BMJ 1996;312:145-148

6. Skinner KA, Helsper JT, Deapen D, et al. Breast cancer: do specialists make a difference? Ann. Surg. Oncol. 2003;10(6):606-615

7. Roohan PJ, Bickell NA, Baptiste MS, et al. Hospital volume differences and five-year survival from breast cancer. Am. J. Public Health 1998;88(3):454-457

8. NIS Technical Documentation. Rockville, MD, Agency for Healthcare Research and Quality, February 2003

9. 1999 HCUP Nationwide Inpatient Sample (NIS) Comparison Report (May 3, 2002) http://www.ahcpr.gov/data/hcup/nisdoc00/nis_comparison_report_1999.pdf (accessed June 1, 2005)

10. Comparative Analysis of HCUP and NHDS Inpatient Discharge Data. Technical Supplement 13, NIS release 5. Agency for Health Care Policy and Research, Rockville MD. http://www.ahcpr.gov/data/ hcup/nhds/niscomp.htm (accessed: June 1, 2005)

11. Deyo RA, Cherkin DC, Ciol MA. Adapting a clinical comorbidity index for use with ICD-9-CM administrative databases. J. Clin. Epidemiol. 1992;45:613-619

12. Charlson ME, Pompei P, Alez KL, et al. A new method of classifying prognostic comorbidity in longitudinal studies: development and validation. J. Chron. Dis. 1987;40:373-383

13. Hannan EL, O’Donnell JF, Kilburn H Jr, et al. Investigation of the relationship beteen volume and mortality for surgical procedures performed in New York State hospitals. JAMA 1989;262: 503-510

14. Harcourt KF, Hicks KL. Is there a relationship between case volume and survival in breast cancer?. Am. J. Surg. 2003;185(5):407410

15. Fisher B, Anderson S, Redmond CK, et al. Reanalysis and results after 12 years of follow-up in a randomized clinical trial comparing total mastectomy with lumpectomy with or without irradiation in the treatment of breast cancer. N. Engl. J. Med. 1995;333:14561461

16. Fisher B, Anderson S, Bryant J, et al. Twenty-year follow-up of a randomized trial comparing total mastectomy, lumpectomy, and lumpectomy plus irradiation for the treatment of invasive breast cancer. N. Engl. J. Med. 2002;347:1233-1241

17. Curran D, van Dongen JP, Aaronson NK, et al. Quality of life of early-stage breast cancer patients treated with radical mastectomy or breast-conserving procedures: results of EORTC Trial 10801. The European Organization for Research and Treatment of Cancer (EORTC), Breast Cancer Cooperative Group (BCCG). Eur. J. Cancer 1998;34(3):307-314 
18. Wellisch DK, DiMatteo R, Silverstein M, et al. Psychosocial outcomes of breast cancer therapies: lumpectomy versus mastectomy. Psychosomatics 1989;30:365-373

19. Kiebert GM, de Haes JC, van de Velde CJ. The impact of breastconserving treatment and mastectomy on the quality of life of earlystage breast cancer patients: a review. J. Clin. Oncol. 1991;9:1059-1070
20. Ganz PA, Schag AC, Lee JJ, et al. Breast conservation versus mastectomy. Is there a difference in psychological adjustment or quality of life in the year after surgery?. Cancer 1992;69:1729-1738

21. de Haes JC, Curran D, Aaronson NK, Fentiman IS. Quality of life in breast cancer patients aged over 70 years, participating in the EORTC 10850 randomised clinical trial. Eur. J. Cancer 2003;39(7):945-951

\title{
Invited Commentary
}

\author{
DOI: $10.1007 / \mathrm{s} 00268-005-1109-3$
}

Jay K. Harness, M.D.

Comprehensive Breast Center, St. Joseph Hospital, Orange, California, USA

The article by Guller and colleagues (DOI: 10.1007/s00268-0057831-z) provides additional support to a concept that has been building over the past few decades: high volumes yield better outcomes. Their analysis is compelling because of the size of their database and the number of years covered by the study. Their findings stand on their own merits, with the primary focus on short-term outcome results (i.e., postoperative morbidity/mortality, length of stay, and discharge status), demographics of the patients and the hospitals, comorbidity, and the primary surgical treatment categories for breast cancer.

The authors have correctly noted the primary limitations of their study; a lack of outpatient and long-term outcome data. More and more, breast-conserving therapy (BCT) is provided in the outpatient setting. Breast ablative therapy (BAT) can be safely provided on an outpatient basis, and it may be combined with a 23-hour admission. It is not clear from the present study if 23-hour admissions are part of the Nationwide Inpatient Samples (NIS) database.

What is it about high-volume hospitals that results in better clinical and economic outcomes in the treatment of breast cancer? Although it appears that the data to answer this question are not included in the NIS database, we can speculate on possible answers. More likely than not, high-volume hospitals would (1) attract higher numbers of specialists (including medical, radiation, and surgical oncologists), (2) have more advanced technologies, and (3) have interdisciplinary breast centers or programs. Perhaps it is these presumed other factors that give high-volume hospitals their better short-term outcomes and different practice patterns (i.e., a higher percentage of BCT vs. BAT). As an example, well-organized interdisciplinary breast centers have pretreatment planning conferences, a part of the patients selection process that generally results in increased numbers of patients being offered BCT.
Most patients facing breast cancer surgery have no way of knowing the relative quality or the operative volumes of the hospitals they may use for their care. Efforts have been made in many states to publish outcome data for high-risk surgical procedures (i.e., cardiac surgery), but little has been done to publish outcomes for low-risk procedures (i.e., breast cancer surgery). What outcome and other data should health care purchasers and patients have access to?

I believe the answer is to expand available national and regional databases to include not only short- and long-term data and outcomes, but also data on surgeon specialization, surgeon case volumes, and the presence or absence of cancer specialty programs (i.e., interdisciplinary breast centers). If these databases can't be modified to include the additional outcomes and data sets, then it may be the role of health care purchasers to demand such information from providers of breast and other cancer services. The benefits of such expanded databases should be obvious for the purchasers of cancer services, but they would also give patients more detailed insights into the providers (i.e., hospitals, surgeons, etc.) they may chose for their cancer care.

An appropriate way to end this commentary is to remind ourselves of a succinct definition of quality of care prepared by the National Institute of Medicine: "Quality of care is the degree to which health services for individuals and populations increase the likelihood of desired outcome and are consistent with current professional knowledge" [1].

\section{Reference}

1. MedicareA Strategy for Quality Assurance. Washington, DC: National Academy Press, 1990 


\section{Invited Commentary}

DOI: $10.1007 / \mathrm{s} 00268-005-1133-3$

Frederick L. Greene, M.D.

Department of General Surgery, Carolinas Medical Center, Charlotte, North Carolina

It is difficult to peruse a modern surgical journal without seeing articles dealing with the relationship of procedural volume and outcomes for either the surgeons or the hospitals in which they practice. Outcome analysis of complex procedures in general surgery supports that the experience of the surgeon and hospital system have major effects on both 30-day mortality and long-term outcomes, especially when cancer-related procedures are analyzed.

Yet another in-depth analysis appears in this issue of the World Journal of Surgery. Guller and colleagues (DOI: 10.1007/s00268005-7831-z), using the power of the Nationwide Inpatient Sample, have rigorously analyzed the fate of women undergoing lumpectomy and mastectomy for breast cancer and have equated outcomes with the volume of patients treated in a particular hospital setting. These authors have studied the adverse factors of morbidity, mortality, increased hospital stay, higher percentage of non-routine patient discharge, and the lower likelihood of performing lumpectomy when indicated.

The authors report that the above adverse parameters are linked to patients who are cared for in hospitals performing fewer than 30 breast cancer procedures per year when compared to hospitals in which more than 70 lumpectomies and mastectomies are performed anually. The authors report the startling finding that women who have undergone lumpectomy at a low-volume hospital are three times more likely to die following their procedure when compared to patients treated in the higher volume centers! Women undergoing lumpectomy and mastectomy have a $73 \%$ and $44 \%$ greater chance of complications when treated at lower volume (less than 30 cases per year) hospitals. It is obvious that the results of this study depend on the analysis of raw data by the authors. We are left with either accepting or rejecting their analysis. While many surgeons performing lumpectomy would be hard pressed to remember a patient who has died within 30 days of the procedure, the advantage (and concern) of large data sets is to compound and accentuate differences among groups.

The authors correctly state that the analysis of low-risk procedures as a result of hospital volume has not been adequately assessed. Obviously system issues are important when the overall management of patients is assessed. Unfortunately the cause of mortality cannot be detected in this analysis. According to Guller and colleagues, patients requiring breast cancer management should be referred to and cared for in high-volume centers. These authors further challenge us to assume that other low-risk surgical procedures should be performed in high-volume centers.

Before payers and others working on "pay per performance" models take these recommendations as gospel, other analyses using a variety of databases should be studied. It is my belief that information from the National Cancer Database, a product of the Commission on Cancer of the American College of Surgeons and the American Cancer Society, will show that community hospitals with small volumes of breast cancer patients provide excellent care for those whom they serve. Our mission is not to recommend that patients and their referral physicians seek care only at large-volume centers. The future of the American healthcare system depends on constantly analyzing outcomes and performance measures with the goal of improving care at all of our inpatient facilities. It is obvious that volume-outcome data must also be extrapolated to countries throughout the world. The issue and challenge of applying balanced care no matter what the size of an institution is a major concern for our patients worldwide. 